\title{
WHY DO PEOPLE COOPERATE WITH MEDICAL RESEARCH? FINDINGS FROM THREE STUDIES
}

Dixon-Woods $\mathrm{M}^{1 *}$, Tarrant $\mathrm{C}^{1}$.

This paper was published as Social Science \& Medicine, 2009, 68 (12), pp. 2215-2222. It is available from http://www.sciencedirect.com/science/journal/02779536. Doi:

10.1016/j.socscimed.2009.03.034

${ }^{1}$ Social Science Applied to Healthcare Research (SAPPHIRE) Group, Department of Health Sciences, University of Leicester.

* Corresponding author. Department of Health Sciences, University of Leicester, 2nd Floor, Adrian Building, Leicester LE1 7RH, United Kingdom. Tel.: p44 116 2297262. E-mail address: md11@le.ac.uk (M. Dixon-Woods).

Keywords: UK, Medical research, Cooperation, Regulation

\section{Acknowledgements}

We wish to thank our co-researchers on the qualitative studies used in this paper: Richard Ashcroft, Paul Burton, Debbie Cavers, Jo Forster, David Heney, Clare Jackson, Sara Kenyon, Joelle Kivits, Kathy Pritchard-Jones, Nilesh Samani, Martin Tobin, Kate Windridge, and Bridget Young. This analysis was funded by ESRC small grant RES-000-22-1908. Mary Dixon-Woods' work on regulation and the medical profession is funded by the ESRC's Public Services Programme (grant RES-153-27-0009). 


\title{
WHY DO PEOPLE COOPERATE WITH MEDICAL RESEARCH? FINDINGS FROM THREE STUDIES
}

\author{
Abstract \\ In this paper, we distinguish decisions about cooperation from decisions about research \\ participation. We offer an empirical and theoretical exploration of why people in three different \\ UK-based medical research projects chose to cooperate. Data analysis of the accounts of \\ 128 participants across the three studies was based on the constant comparative method. \\ Participants' cooperation was engaged by a perception that they would be contributing to the \\ 'public good', but they also wanted to justify their decision as sensible and safe. Critical to \\ their cooperation was their belief that researchers would fulfil their side of the cooperative \\ bargain, by not exposing participants to risks of harm or exploitation. Although participants \\ were generally unaware of the details of the regulatory regime for research, they \\ demonstrated a generalised reliance on regulation as a feature of everyday life that would \\ provide a safe context for cooperation. In their assessment of particular projects, participants \\ made judgements about whether to cooperate based on more specific cues, which acted as \\ signs to assure them that researchers shared their cooperative intentions. These cues \\ included organisational and professional credentials, the role identities and perceived \\ trustworthiness of those involved in recruiting to research, and visible signs of reasonable \\ practice mandated by regulatory systems. Thus participants drew on their understandings of \\ an institutional field that was much broader than that of research alone. We propose that the \\ social organisation of research is fundamental to the judgements people make about \\ cooperation with research. Cooperation may be a more useful way of thinking about how \\ people come to engage in collaboratively oriented actions such as research participation, \\ rather than currently dominant individualistic models. Attention to the institutional context of \\ research is critical to understanding what makes cooperation possible, and has important \\ implications for the design of regulatory regimes for research.
}




\section{Introduction}

Questions about why people engage in cooperative behaviour have been a long-standing interest of the social sciences (Halfpenny 1999), going back to the work of Durkheim (1984) on pre-contractual solidarity. A very large body of work in economics and psychology has explored cooperation, much of it using game theory. Sociological studies of cooperation have been undertaken under various rubrics, including altruism and reciprocity, and have focused on a diverse range of areas, including the family, charitable giving, blood and organ donation, and helping people escape persecution. In this paper we focus on people's cooperation with medical research. We define medical research broadly as the scientific study of health and illness, though we recognise that the term escapes straightforward and exclusive specification. We propose that the social organisation of research is fundamental to the judgements people make about cooperation with research, and that cooperation may be a more useful way of thinking about how people come to engage in collaboratively oriented actions such as research participation, rather than currently dominant (and individualistic) models such as those concerned with the adequacy of consent.

We begin by making an important distinction between cooperation and decisions about participation. A burgeoning literature on research participation has aimed to understand individuals' reasoning, motives, and beliefs, and other factors that influence the decisions they make about participation. This literature has identified the values and characteristics of individual participants (e.g. Fry \& Dwyer 2001), people's perceptions of the benefits of participation, such as the possibility of securing better treatment and specialist attention (Slevin, Mossman, Bowling, et al. 1995; Wendler et al, 2008), risks, costs and benefits of participation (Lowton 2005) and aspects of information (Ellis, 2000: Jenkins and Fallowfield, 2000 ) that are relevant to such decisions. But participation is distinct from cooperation. While participation focuses on an individual's involvement in a matter or event, cooperation necessarily involves joint action or coordination with other parties. Drawing on a number of different approaches, we will, for purposes of this paper, define cooperation as purposeful personal contribution to a common effort. Cooperation, crucially, individuals' beliefs about the cooperative intentions of the other parties involved in the effort (Pruitt \& Kimmel, 1977) as well individuals' own motives for cooperation. Thus, for example, it is possible that individuals might be keen to join a research project (for example to gain access to new treatments) but might decline an invitation to do so if they are sceptical of the cooperative intentions of the researchers/research community. 
Medical research is an interesting area for scholarly work on cooperation because of two features. First, it has many of the characteristics of a public good or a commons, with the attendant familiar dilemma that it may impose costs or burdens on those who contribute (such as volunteering personal information, contributing biological materials, undergoing additional tests or invasive procedures, or making extra visits to clinics), while allowing many to benefit. The research effort therefore depends on engaging the cooperation of those with the potential to contribute. But its second characteristic is that it appears, on the face of it, rather an unpromising candidate for securing cooperation: it involves risks, including those that derive from the fact that the interests of researchers may not always be identical to those of research participants. Commercial organisations or individual researchers' careers can, for example, profit from the voluntary contributions of participants. A history of scandals has served to heighten awareness of risks of mistreatment and exploitation; physical, psychological, and emotional harms; and assaults on human rights and dignity (Dixon-Woods and Ashcroft 2008), demonstrating that the research community cannot always be trusted to have cooperative intentions. Taken together, these potential risks and burdens would seem to pose challenges related to fairness and exploitation, which generally undermine people's tendency to cooperate (Fehr \& Schmidt, 2001). Given this, why would individuals choose to cooperate with medical research, and what are the conditions necessary for their cooperation?

These are important questions, not least because a focus on cooperation affords a perspective on how decisions about participation may be socially organised, even when they appear to be highly individual. It directs attention in particular to the institutional and organisational features that help to structure and shape individuals' interests, desires, decisions and actions, and the accounts they give of these (Lawrence \& Suddaby, 2006; Powell and Colyvas, 2008). In particular, it encourages a recognition of how institutional forces frame the possibilities for choice and action, where institutions are understood, following Ostrom (2005), as the prescriptions that humans use to organise all forms of repetitive and structured interactions, including institutionalised cultural rules as well as formal organisations.

This argument is consistent with recent approaches in the sociological literature on charitable behaviour that stress the socially embedded nature of individuals' philanthropic endeavours (Ostrander, 2007), and see recipient organisations' tactics and practices, efficiency, resources, and logistics as helping to shape the behaviour of donors. Similarly, in his analysis of blood and organ donation, Kieran Healy (2006) argues that 'giving' is structured, promoted, and made logistically possible by the organisations and institutions that have interests in securing such giving. Healy recognises that organisations do not simply manipulate their donors; rather, the discourses and resources available to organisations to secure cooperation are dependent on social and institutional contexts. 
These kinds of analyses encourage a recognition of both researchers and research participants as located within an institutional field. For medical research, this includes an extensive regulatory apparatus aimed at ensuring safe and ethical conduct of research, and that participants are not exposed to undue risks of harm. In the UK, the Research Governance Framework (RGF) for Health and Social Care (Department of Health 2005), governs virtually all research conducted within the National Health Service (NHS). It begins by recognising the possible benefits of research, but emphasises the possible risks and the consequent need for governance, and the public's right to have:

\section{[...] confidence in, and benefit from, quality research in health and social care. The} public has a right to expect high scientific, ethical and financial standards, transparent decision-making processes, clear allocation of responsibilities and robust monitoring arrangements. (2005: 2)

The RGF further emphasises the responsibilities and accountability of researchers. It institutes a series of external controls over what researchers are permitted to do, including the requirement that all research involving patients be approved by a Research Ethics Committee and receive research governance approval from the organisations where the research is to be conducted. The regulatory regime for research extends well beyond the RGF, and also includes many other actors, legal instruments, and formal institutions. Taken together, the regime directly or indirectly structures what researchers are allowed to do and say about their own projects, but seeks also to structure the ways in which people respond to research as an institution. By constructing an accountability regime and associated rules and structures, cooperation is thus invited on grounds that formal governance procedures allow people to be confident that any risks are controlled and managed and their safety can be assured.

The formalisation and codification of this regulatory regime for research might be seen as a turn towards a 'confidence' based approach, where confidence is seen as secured through use of formal rules, legalistic procedures, contractual forms, and the availability of monitoring and sanctioning procedures, away from a 'trust' based approach, which relies on ethical relations that are not conditioned by an external framework of controls (Tonkiss and Passey, 1999; Checkland, Marshall, \& Harrison 2004; Harrison \& Smith 2004; Smith 2001). At a policy level, it is no longer seen as sufficient to place trust in researchers' own moral and ethical frameworks to ensure that research will be conducted safely and ethically. Rather, formal regulatory frameworks such as the RGF explicitly self-identify as being directed towards gaining people's confidence by providing a rational basis for their engagement, and thus avoiding the lack of accountability and potential for lapses associated with trust-based approaches (Dixon-Woods and Ashcroft, 2008). A vocal critique has pointed to the importance of trust in medicine and medical research, and the risk that rule- and contractbased forms of regulation may do violence to trust, with negative consequences (Checkland, 
et al 2004; O'Neill 2004). Despite this, there is surprising little empirically informed understanding of the basis of people's cooperation with medical research, and the extent to which these kinds of regulatory interventions are salient to the grounds on which people make their decisions to cooperate. Using people's accounts of taking part in three different biomedical research projects, this paper explores people's accounts of cooperation with medical research, and reflects critically on the role of regulation.

\section{Methods}

This paper is based on analysis of data from qualitative studies of participants' experiences of being invited to take part in three different biomedical research projects. These qualitative studies, all approved by an NHS Research Ethics Committee, are briefly (for reasons of space) described here and in Table 1, with references to published papers that provide further detail of the methods. These three studies were chosen because they all provided insights into why people might engage in a research effort, but also allowed for contrast and comparison across different contexts of participation. Two studies (those of tissue banking and GRAPHIC) had specifically explored views of regulation of research.

The Childhood Cancer and Leukaemia Group (CCLG) tissue banking study was a study of parent and child experiences and views of being asked to donate 'surplus' tumour material left over after biopsies or excisions to a national childhood cancer tissue bank for research. It involved semi-structured interviews with a purposive sample of 42 families ( 41 mothers, 18 fathers and 20 children), recruited from seven tertiary centres for the treatment of childhood cancer across the UK (Dixon-Woods, Cavers, et al., 2008; Dixon-Woods, Wilson, Jackson, Cavers, \& Pritchard-Jones, 2008).

The GRAPHIC participant study was a study of people's experiences and views of being asked to take part in a genetic epidemiology study of blood pressure regulation. GRAPHIC aimed to develop a phenotyped resource of nuclear families and involved healthy volunteers providing a blood sample for DNA analysis, wearing a blood pressure monitor for 24 hours, and responding to a nurse-administered questionnaire. The qualitative study involved semistructured interviews with a purposive sample of 29 participants from Leicestershire (DixonWoods, Ashcroft, et al., 2007).

The ORACLE participant study was a qualitative study of women's experiences of being involved a randomised, placebo-controlled clinical trial, which investigated whether specific antibiotics were effective in prolonging pregnancy and improving outcomes in women with signs of pre-term labour. Semi-structured interviews were carried out with a purposive sample of 20 participants from the Trent region, UK (Kenyon, Dixon-Woods, Jackson, Windridge, \& Pitchforth, 2006). 
In total, 128 interviews contributed to the analysis reported in this paper.

A systematic and iterative method of analysis based on the constant comparative method (Glaser \& Strauss 1967) was used. We were concerned with the development, specification and integration of categories with theoretical purchase. In order to allow connections to be identified and comparisons to be made systematically between the accounts given by different participants in different contexts, the data were first organised into thematic charts. A set of themes and subthemes relating to cooperation were identified for each study based on careful reading and comparison of extracts of coded text. The data from each study were then summarised onto a separate chart, representing each participant's account for each theme and sub-theme. These charts were used to draw up a single, higher-level chart which summarised the findings from each study under the key overarching themes. The summaries in the higher-level chart were compared across the studies to generate a coding scheme, refined following discussion with the qualitative researchers who conducted the primary data collection and analysis. The coding scheme was used to assign data to categories using QSR N6 software, with categories adjusted and modified to ensure adequate fit with the data as coding proceeded. Quotations used in this paper are anonymised, and labelled with an ID number with the prefix $T$ to denote that the quotation comes from the tissue banking study, $G$ the GRAPHIC study, and O the ORACLE study.

\section{Results}

The three studies, all 'non-commercial', differed in significant ways. The GRAPHIC study was perhaps the most evident example of where those participating made their contribution with little expectation of a personal gain, as it involved healthy volunteers who were not themselves known to be affected by a disease. The initial recruitment attempt involved no personal contact, as potential participants were sent recruitment material by post and were then later contacted by a study research nurse. The tissue banking study was involved no personal gain for those contributing, though benefits might accrue to a fairly well-defined population - those affected by childhood cancer. Consent for the procurement and banking of tissue was sought by (usually familiar) staff involved in the care of the child with cancer, either before or after the surgery where it was removed for therapeutic reasons. The ORACLE trial was in many ways quite distinct. It involved a possible benefit to those who participated, in the sense that it was possible that the interventions being studied might have improved outcomes - but there was no certainty of this, and it was also possible that there might be a negative impact. Unlike the other two studies, those who participated were recruited during a health crisis by unfamiliar professional staff. Despite these important differences between the studies, and the different motives people had for participation, one of our most striking findings was that of the similarity of the accounts of cooperation given across the studies. 


\section{Medical research as a public good}

A vivid feature of the accounts, across all three studies, was their emphasis on the moral character of research participation, and in particular the status of medical research as a public good to which responsible people should contribute. To some extent this is evidence of the more general attempt to defend moral character found in most accounts of action. But more specifically, this finding is consistent with Healy's (2006) argument that people are likely to cooperate with a voluntary endeavour only if they can produce a moral account of their actions, and is also consistent with the idea that people enjoy the benefit of a 'warm glow' when they do engage in this kind of cooperative behaviour (Andreoni, 1990).

Well research is important and it's only by people, well really trial and error that you find out exactly what will work and what won't work and if I can help somebody else in a couple of years time cos l've been on this trial then all well and good $(\mathrm{O} 4)$

If they didn't do this in the past the treatment now wouldn't be there really would it? As soon as you hear the research for future [...] that was all I needed to know, the fact that it would be used for future to help other people (T2)

\section{Risks and safety}

Clearly, accepting an invitation to serve the public good allowed participants to display their moral character and gain intrinsic pay-offs. But, importantly, there was a recognition that it would not be seen as morally deviant to decline the invitation either. This was because participants' eagerness to serve the public good was tempered by some wariness. Many (though not all) explicitly recognised medical research was not always for a 'good cause', safe, or ethical, and they used examples such as 'scandals' or evidence of poor practice to demonstrate this.

I know medical research is sometimes open to argument, it's important, I mean the MMR scare is the one that really brings home to you how research in inverted commas can be used inappropriately or, you know, can be quite difficult to make sure it's to everybody's benefit (G7)

I was a bit apprehensive because I thought, you know, sometimes you hear stories of medical research like how things go wrong $(\mathrm{O} 14)$

In Healy's (2006) analysis of blood and organ donation, he argues that an excess of altruism is not seen as culturally plausible - for example, an individual who wishes to give away a kidney to help an unidentified other would be regarded with suspicion. Similarly, our data suggested that people felt they could not reasonably be expected to accept undue risks in the 
interests of others, and their accounts thus demonstrated that the option of declining an invitation to participate in research was culturally available. Indeed, it seemed that it was often important for women in the ORACLE study, who were making decisions on behalf of their unborn child, to construct accounts that explicitly defended their decision. These women were keen to show that they had reflected on potential risks before cooperating. In accounts that displayed rationalisations and trade-offs of perceived risks and benefits, they explained how the possible benefit to their babies from the treatment being tested in the trial had provided a good reason for accepting a small amount of risk.

The risk to [baby] you know, because he was dependent, everything was like on me and I wanted to make the right decision for him [...] I wouldn't want to put an unborn baby at risk if there was any risk (O13)

All right it might keep it [baby] in, but would it cause brain damage or its lungs not grow properly and stuff? But then I think the fact that your baby, if it's born that early, could have so many other things wrong with it anyway sort of overrides that. It's just like well if that may help then yeah. (O16)

Participants in the tissue banking study were similarly concerned that their child should not be exposed to unnecessary risk, but the types of risks they identified differed markedly from those perceived by the ORACLE participants. Parents perceived that there was little risk of physical harm associated with obtaining tissue for research, as the surgery where it was removed would be undertaken for therapeutic reasons anyway. They did, however, identify risks of exploitation, including the possibility that surgeons might take extra tissue for research, or that the tissue might not be put to good or appropriate use. These might be characterised as concerns about becoming 'a mark' (Goffman 1952) - someone who is the victim of a scam.

I would prefer it if it was just basically medically you know for a cure or looking into why these things happen and there's ways of preventing them and everything, rather than something like cosmetics or things along those lines, which I'm sure it possibly won't be used for that. (T64)

I would hope that it's kept by the correct people [...] I wouldn't like to see it used by anyone else to be honest anyone that's in that kind of [making] money out of something like that (T30)

In the GRAPHIC study, participants often identified possible benefits (such as "warm glow" and getting the results of health checks) and had difficulty identifying potential risks, and any risks identified were felt to be minimal and very unlikely. These accounts again defended the 
decision to take part as reasonable, demonstrating people's expectations that they would not come to any harm through their participation.

\section{CAN YOU SEE ANY RISK TO YOU IN PARTICIPATING?}

No, well clinical risks of an infected needle of something like that, so minimal as to be ignored, no risks, not at all

ANYTHING ELSE AT ALL?

No (G5)

It is clear that cooperation with any particular research project was conditional on participants being able to construct moral accounts of their decisions that allowed them to show that they were contributing to the common good, and hence to gain intrinsic pay-offs from their decision to cooperate. But it was also important that they could feel confident that their decision had not been taken irresponsibly or stupidly - that they expected those conducting the research to reciprocate by acting cooperatively in return, by not exposing them to physical harm or exploiting their tissue or personal data. This raises the question of the grounds on which these beliefs and expectations underpinning decisions to cooperate were based.

\section{Regulation}

In none of the three studies did regulation appear spontaneously in any account of why participants chose to cooperate. In two studies (GRAPHIC and tissue banking), participants were specifically asked about the regulation of research. When prompted, participants described regulation as a form of background reassurance; they assumed that research was regulated, but were unsure of the details of how. Most participants were unfamiliar with Research Ethics Committees (RECs), but were not surprised to learn that they existed, and were able to describe what they thought their role in governing research might be: to police the (legal and ethical) boundaries for research. They sometimes explicitly referred to previous scandals involving research as part of the rationale for having such oversight.

Perhaps as a result of mistakes that have been made before, yes, I think people are obviously looking at it and thinking, 'well, you know, we can't make those sort of mistakes again.' [...] there's so many preliminary checks made now (G8)

There is some experimental evidence to suggest that having sanctioning systems may damage trust by encouraging the view that those to whom the sanctions apply act in their own interests and lack the internal motivation to do good (Mulder et al 2006). The very existence of policies, frameworks, and procedures might be interpreted as signals of danger. But our data are more consistent with Sztompka's (2007) argument that governance can have a protective role in providing an environment in which cooperation can flourish: it allows those 
with cooperative intentions and motivations to cooperate safely, building cooperative norms within the community, in the knowledge that defectors (those who harm or exploit others) will be subject to punishment.

I'm assuming that there's certain things they can do and certain things they can't do but purely that every other aspect of life is fairly tightly controlled by the government and by the law so you assume that areas like this would be controlled as well (G24)

Obviously there must, everything must be monitored, you know, this is the way, this is what we do, these are the paths we go down (T13)

Participants' accounts demonstrated little familiarity with the specifics of regulation for medical research, but rather a more generalised reliance on regulation as a feature of everyday life. In their assessment of particular projects, participants made judgements about whether to cooperate based on more specific cues, including: organisational and professional credentials; interpersonal trust; and visible signs of reasonable practice.

\section{Organisational and professional credentials}

Gambetta and Hamill (2005) report that people seek cues and other signs as signals of the properties that are relevant to trustworthiness. Similarly, participants across the three datasets described relying on various cues in coming to their judgements about the values and trustworthiness of the research they were asked to take part in. They reported using organisational and professional credentials as the basis of their confidence that the research would work in accordance with the Mertonian ideals of science (Merton 1973). This meant they held 'reasonable expectations' (Parker 2005) that the research would be legitimate, would produce benefits for society, and be safe and ethical. Such credentials gave people grounds to assume that the cooperative intentions of the researchers were sound. Thus, even though the tissue banking study was conducted not long after a major public UK scandal involving retention of children's organs and bodily materials following post-mortems (Redfern, 2001), parents who were interviewed were nonetheless confident that any samples contributed by their children would be handled appropriately:

You talk about the ethical use of samples, but to a certain degree I think in that situation you'd automatically assume that [...] l'd trust that they, you know it would be done ethically (T20)

Participants' accounts frequently identified research as involving collectivities or coalitions of individuals, organisations and institutions that they perceived to have a high degree of what Sitkin and Roth (1993) term 'value congruity'. Expectations of moral conduct by other 
members of the collectivity were fundamental to their decisions of participants to cooperate by making their own investment in the coalition.

You just assume as a member of the public anything that goes on in hospitals is all above board and is within reason obviously [....] they're NHS laboratories, universities or hospitals with people who work for the NHS or whatever and that's it. Or if it was a private company again it was to if this was farmed out to private companies it was for the great good to find a cure for cancer. [...] Nobody's trying to do anything underhanded here, this is above-board, we're trying to cure cancer. (T21)

I think we all simply assumed that it was going to be carried out in a proper fashion and so it was. [...] I suppose the fundamental belief that the vast majority of people who are involved in medicine and its allied professions, I mean research, are dedicated professionals. [...] People who go into that walk of life are doing it because they want to do it and they're just dedicated. (G17)

These data tell us something about the values to which participants subscribe. They also indicate that participants expect values of cooperation and commitment to disinterested medical progress to be shared throughout the social world (Dixon-Woods, Wilson, et al. 2008a) of medical research. These expectations to a large extent are expectations of reciprocity: that if individual participants act from goodwill and contribute to research, research will be conducted in the spirit of goodwill and contribute to the public good. Importantly, these assumptions were not specific to, nor derived solely from, a view of the institution of research: rather, in large part, they were 'borrowed' from broad expectations of other institutions: the health service, the organisation where the research was being conducted, and the professionals involved in recruitment. These accounts thus demonstrate the relevance of the institutional context in which people choose to co-operate, but also suggest that the (formal) institutional context that is salient for participants is not that specifically of research, but rather is primarily that of medicine and healthcare. Reassurances that came from those bearing the appropriate credentials were particularly valued:

You have to put your trust in their hands don't you? And you just feel, you're just guided by really the consultants, you're guided by the nurses and the doctors [...] they were in the medical profession. (T13)

I mean you know that the people that're taking it they are professional people who are striving to find cures and better treatments you know so I mean whatever they decide they need to use it for to the greater good of others it can't be wrong can it? (T66)

I asked about it, yeah, and they, and nurse assured me (O19) 
These findings point to how people respond to social life on the basis of categories. Members of the health professions, and institutions such as the NHS, were taken to have good motives and to act in the public interest because, as Potter and Wetherell (1987:116) put it, they were 'taken to be members of relatively enduring categories, and in virtue of their category membership inferences are made from the attributes of individuals to the attributes of the rest of the category'.

\section{Interpersonal trust}

As Lowton's (2005) has also reported, a distinct but related element of participants' assessment of whether cooperation was warranted relied on interpersonal trust. Interpersonal trust, as described by participants, was created through 'facework' (Giddens 1990), where encounters between recruiters and those being asked to take part had characteristics of trustworthiness, including qualities of friendship, respect, and politeness. Participants held the belief that professionals had their best interests at heart, because these were the people helping them or their child, and hence strongly believed that they would not expose them or their child to unnecessary risk. The safety associated with the institution of the health professions thus helped to augment perceptions of the safety of research. In the tissue banking study, participants described relying on trust built through relationships with particular individuals to manage or bracket the risks and uncertainties involved in taking part in research. Parents relied on the trust they had already invested in the professionals caring for their child, often during repeated and intimate interactions, to provide assurances that their child would not be exposed to unnecessary harm.

Because he knows so much about your child and the condition and everything I think it makes you feel a bit more comfortable 'cos he'd only do what he thought was best for your child. (T1)

[I did] not think for one minute the surgeon that we had would be motivated by any other [than] altruistic means and or motives (T7)

Participants in the ORACLE trial also referred to the fiduciary nature of their relationship with the doctors, midwives, and nurses, but in this situation they had to rely on 'swift trust' (Meyerson, Weick, \& Kramer 1996) rather than trust built up over repeated interactions.

I was confident with the doctors who suggested it and went with them really (O11)

'Swift trust' can be formed quickly in temporary groups or encounters to enable people to cooperate under conditions of vulnerability, uncertainty and risk. It relies heavily on perceptions of others' role categories, and the enactment of 'technically competent role performance' (Barber 1983: 9) which engenders positive expectations, as well as behaviour 
that signals the other party's trustworthiness (Dibben, Morris, \& Lean 2000), as also indicated by the GRAPHIC participants. It was thus evident across all three studies that interpersonal trust, in this sense, was institutionally located: though participants responded to individuals' personal qualities, they saw also professionals as bearers of warrants.

\section{Visible signs of reasonable practice}

Our data across the three studies suggested that the provision of information, and the enactment of the 'informed consent' process, were important not so much as means for participants to gain information to inform their decision-making process, but rather as cues that the cooperative bargain would be fulfilled.

I didn't really need to know all the ins and outs of it all [...] you don't need all the details of what they are going to do if you agree to do it and you know they're ok (G3)

These routines functioned as visible signs of reasonable practice, but also signals of openness, trustworthiness, honesty and good intentions on the part of the researchers to act within a cooperative model.

I suppose part of the process that NHS, [hospital] was there, [University] and it was you know, three well known, well respected organisations so the amount of information I received was sufficient for me to make a decision. If it had been from Joe Bloggs, you know, bio whatever, I wouldn't have even responded. It would've gone in the bin [...] it gives it credence; it gives it the stamp of approval really (G6)

I think the nurse explained it to me really well. I was really pleased with the way she'd explained it to me. I mean she weren't sort of putting on any pressure or, she'd explained it in a way that I could only see, you know, I could see more benefits than anything else to it, so. (O5)

Documentary evidence of 'warrants of trust' was especially important to participants in the GRAPHIC study. Logos and assurances of affiliation with hospitals and universities in the recruitment paperwork were described as critical cues by people in distinguishing between research carried out by NHS organisations, and other organisations - such as pharmaceutical companies - in which they had less trust.

it was like this, you know, the NHS on the top, official paper shall we say, it was official paper [...] I wouldn't have done it for just, I wouldn't of had needles, somebody put needles into me if they weren't, National Health Service (G26) 


\section{Discussion}

Our analysis of three different studies of accounts of being asked to take part in medical research demonstrates the extent to which individual decisions may be socially organised. We propose that medical research can be understood as an example of what Mancur Olson (1971) terms collective action, one where collaboration and cooperation are required between a range of parties. Those who cooperate with medical research want to show that they have contributed to the public good and demonstrated kinship and fellow-feeling, but they also want to demonstrate that they were not stupid, gullible, and foolhardy in so doing. Attention to the institutional context of research, and the social relations between participants and researchers, is thus critical to understanding what enables cooperative behaviour by research participants. Our analysis suggests that, notwithstanding any benefits that may occur to individuals, participation in medical research is characteristically understood by unpaid research participants as a contribution to a public good. It has identified what participants feel is the researcher's side of the cooperative bargain, and what signs they rely upon for reassurance that researchers share the same cooperative intentions. People recognise that research may be potentially risky, and sought assurances of safety. Safety in this context ranged from protection from direct physical harms through to affirmation that participants were not being 'taken for a ride' (duped, suckered, or conned) by cooperating with researchers. Decisions about cooperation were not thoughtless, irrational, or undiscriminating. But people also did not make decisions in ways that would be seen as 'fully reasoned'. Their decisions were set against a context of beliefs about shared social norms, visible evidence of trustworthiness, the assumed existence of a regulatory system and symbolic evidence of regulatory and institutional safeguards, giving participants what they saw as good reasons to believe the risks are low.

We drew on data on participants' views of being asked to participate in three very different medical research studies, and this allowed us to identify some common aspects of people's accounts of their decisions. A limitation is that our data only involved people who did consent to participate in medical research, not those who declined participation or dropped out of the primary studies. It also did it not involve those asked to take in 'commercial' studies. Those who did not consent may have very different views, including a very different orientation towards cooperation. Nonetheless, our data provided clear evidence that people's reasoning and engagement were actively structured by the institutional field in which research projects were located.

Our data suggest that decisions about cooperating with research often functioned at the level of heuristic. There was evidence of a strong tendency to make category-based inferences to inform assumptions about the motives and interests of those conducting and recruiting to research, and to assume value congruity. Using category-level inferences about the 
trustworthiness of the institutions and organisations involved in research reduced the cognitive and emotional demand of the decision, enabling people to make decisions that they felt were consistent with their values and preferences without having to consider all information. Regulation was important as a form of background reassurance, but the specific details of the regulatory code appeared to be of little salience. Participants recognised that they could not police the research themselves; they instead argued that it was reasonable for them to assume that there would be a set of formal arrangements for the governance of research, and that other parties were managing the risks sufficiently well that they had no need to worry. Such an analysis is consistent with Starr's (1985) argument that people's acceptance of risk that is not directly under their control depends on their assumptions about the existence and reliability of risk management, and that violations will be sanctioned (Fehr \& Fischbacher 2004). This meant that the detail or content of various communications was relatively unimportant to participants; what was important was their symbolic value: that the proper rituals were enacted, and the available cues were the right ones. In making judgements about the goodness and safety of particular studies, participants engaged in monitoring of visible signs of 'reasonable practice' (Power 1999) of the kind that might be mandated by a regulatory regime, and responded to aspects of the 'front stage' of research projects. An important consequence of this, from a regulatory perspective, is that the increasing standardisation and routinisation of recruitment procedures required by regulatory processes (Dixon-Woods et al, 2007) may inadvertently reduce the level of monitoring that people engage in by providing cues on which people uncritically rely.

Importantly, the role identities of particular professionals and institutionally located interpersonal relations helped to confer legitimacy and secure people's cooperation. The notion of researchers and health professionals as trusted agents, and beliefs about professional morals and ethics, were highly relevant to participants despite a regulatory turn away from relying on trust and professional agency as means of managing risk. Doctors, nurses, and other health professionals acted as intermediaries in the sense described by Coleman (1994) where they acted as guarantors of the propriety of the research project to which they were recruiting. The field of research thus in some senses 'grazes the commons' (Offer, 1996) or trades on the field of healthcare (specifically the institutional frame of the $\mathrm{NHS}$ ) and the healthcare professions, and their associated credibility and credentials.

Our analysis therefore suggests that the social organisation of research is fundamental to the judgements people make about cooperation. It further suggests that cooperation may be a more useful way of thinking about how people come to engage in collaboratively oriented actions such as research participation, rather than currently dominant (and individualistic) models such as those concerned with the adequacy of consent. Our findings also challenge influential literature which has advanced a theoretical distinction between trust and confidence, and led to a polarised view of regulatory approaches as either trust- or 
confidence-based (e.g. Checkland et al, 2004). The distinction between trust and confidence was difficult to discern empirically in our data. People appeared to orient towards research based on positive expectations about what occurs within a community with commonly shared norms and a high degree of value congruence, as well as relying on fiduciary aspects of their relationships with health professionals, thus conforming to a trust-based model. But they also relied on assumptions about constraint and oversight that were much more consistent with a confidence-based model. Thinking about cooperation rather than trust or confidence helps to direct our attention to how judgements and actions that might at first glance appear individual (such as consent), are in fact institutionally and organisationally structured.

\section{Conclusions}

Securing cooperation with medical research requires that participants are able to produce an account of their actions that demonstrates first, their moral qualities, and second, that they have not been reckless as to their own safety and integrity. Our evidence across three different studies confirms that the social organisation of medical research is critical to these accounts. Our analysis sees people as agentic, but identifies how their reasoning, judgements and actions in relation to cooperation are institutionally structured. But the relevant institutional field is not a single, well-defined one solely comprising research activities, and indeed the regulatory regime for research is salient only in so far as regulation is assumed to be a feature of everyday life. As conceived by participants, the salient institutional field is a broader field including healthcare and the health professions, governed by cooperative norms and oriented towards serving the public good. It is on the basis of this wider field, and its resources of credibility, credentials, reputational capital, and background assumptions about oversight and control, that people cooperate. Regulatory effort might usefully focus on how to ensure that people's expectations about the cooperative norms in operation in the field of research can best be upheld rather than, perhaps, the routinisation of visible signs of reasonable practice at the recruitment stage. 


\begin{tabular}{|c|c|c|c|}
\hline & Potential participants & Recruitment & $\begin{array}{l}\text { Semi-structured } \\
\text { interviews by social } \\
\text { scientist }\end{array}$ \\
\hline $\begin{array}{l}\text { CCLG tissue } \\
\text { banking } \\
\text { study }\end{array}$ & $\begin{array}{l}\text { Families from seven UK } \\
\text { childhood cancer treatment } \\
\text { centres: } \\
\text { - With a child diagnosed with } \\
\text { cancer }>6 \text { months previously } \\
\text { - Not experiencing health } \\
\text { crisis } \\
\text { - Mix of social and ethnic } \\
\text { background, different tumour } \\
\text { types, age of child }\end{array}$ & $\begin{array}{l}\text { Families approached by } \\
\text { hospital staff } \\
42 \text { families ( } 41 \text { mothers, } 18 \\
\text { fathers, } 20 \text { children) consented }\end{array}$ & $\begin{array}{l}\text { Exploring views on consenting } \\
\text { to tissue donation (2004-5) }\end{array}$ \\
\hline $\begin{array}{l}\text { GRAPHIC } \\
\text { participant } \\
\text { study }\end{array}$ & $\begin{array}{l}\text { GRAPHIC study participants } \\
\text { who had agreed to be } \\
\text { contacted about further studies } \\
\text { ("healthy" volunteers } \\
\text { registered with GPs in } \\
\text { Leicestershire, UK): } \\
\text { - Mix of position in the family } \\
\text { (parent/offspring), gender, } \\
\text { willingness to be involved in } \\
\text { research }\end{array}$ & $\begin{array}{l}\text { GRAPHIC participants invited } \\
\text { to qualitative study by } \\
\text { GRAPHIC principal } \\
\text { investigator } \\
29 \text { individuals ( } 16 \text { men, } 13 \\
\text { women) consented }\end{array}$ & $\begin{array}{l}\text { Exploring participants' } \\
\text { experiences and views of } \\
\text { being recruited to the } \\
\text { GRAPHIC study (2005) }\end{array}$ \\
\hline $\begin{array}{l}\text { ORACLE } \\
\text { participant } \\
\text { study }\end{array}$ & $\begin{array}{l}\text { ORACLE participants (women } \\
\text { in the Trent region who } \\
\text { requested trial results): } \\
\text { - Socially diverse (non- } \\
\text { purposive sampling) }\end{array}$ & $\begin{array}{l}\text { ORACLE participants invited } \\
\text { to qualitative study by } \\
\text { ORACLE Principal Investigator } \\
20 \text { women consented }\end{array}$ & $\begin{array}{l}\text { Exploring perceptions of the } \\
\text { results of the trial and } \\
\text { women's experiences of being } \\
\text { recruited to and participating in } \\
\text { the ORACLE trial (2004) }\end{array}$ \\
\hline
\end{tabular}

References

Andreoni, J. (1990) Impure altruism and donations to public goods: A theory of warm-glow giving. The Economic Journal, 100, 464-477.

Barber, B. (1983). The logic and limits of trust. New Brunswick, N.J.: Rutgers University Press. 
Checkland, K., Marshall, M., \& Harrison, S. (2004). Re-thinking accountability: Trust versus confidence in medical practice. Quality \& Safety in Health Care, 13, 130-135.

Coleman, J.S. (1994) Foundations of social theory Cambridge, Mass: Harvard University Press

Department of Health. (2005). Research governance framework for health and social care (second edition). London: Department of Health.

Dibben, M. R., Morris, S. E., \& Lean, M. E. (2000). Situational trust and co-operative partnerships between physicians and their patients: A theoretical explanation transferable from business practice. QJM : Monthly Journal of the Association of Physicians, 93, 55-61.

Dixon-Woods, M., Angell, E., Ashcroft, R. E., \& Bryman, A. (2007). Written work: The social functions of research ethics committee letters. Social Science \& Medicine, 65, 792-802.

Dixon-Woods, M., \& Ashcroft, R. E. (2008). Regulation and the social licence for medical research. Medicine, Health Care, and Philosophy, eprint July.

Dixon-Woods, M., Ashcroft, R. E., Jackson, C., Tobin, M., Kivits, J., Burton, P., et al. (2007). Beyond 'misunderstanding': written information and decisions about taking part in a genetic epidemiology study. Social Science \& Medicine, 65, 2212-2222.

Dixon-Woods, M., Cavers, D., Jackson, C. J., Young, B., Forster, J., Heney, D., et al. (2008). Tissue samples as "gifts" for research: a qualitative study of families and professionals. Medical Law International, 9, 131-150.

Dixon-Woods, M., Wilson, D., Jackson, C., Cavers, D., \& Pritchard-Jones, K. (2008). Human tissue and 'the public': the case of childhood cancer tumour banking. BioSocieties, 3, 57-80.

Durkheim, E. (1984). The division of labour in society. London: Macmillan. 
Ellis, P.M. (2000) Attitudes towards and participation in randomised clinical trials in oncology: A review of the literature. Annals of Oncology. 11: 939-945

Fehr, E \& Schmidt, K. M. (2001). Theories of fairness and reciprocity. Discussion Papers in Economics 14, University of Munich, Department of Economics.

Fehr, E., \& Fischbacher, U. (2004). Social norms and human cooperation Trends in Cognitive Sciences, 8, 185-190.

Fry, C., \& Dwyer, R. (2001). For love or money? an exploratory study of why injecting drug users participate in research. Addiction, 96, 1319-1325.

Gambetta, D., Hamill H. (2005) Streetwise: How taxi drivers establish their customers' trustworthiness. New York, Russell Sage.

Giddens, A. (1990) The consequences of modernity California: Stanford University Press

Glaser, B., \& Strauss, A. (1967). The discovery of grounded theory. Chicago: Aldine.

Goffman, E. (1952). On cooling the mark out: Some aspects of the adaptation to failure. Psychiatry: Journal for the Study of Interpersonal Processes, 4, 451-463.

Halfpenny, P. (1999). Economic and sociological theories of individual charitable giving: Complementary or contradictory? Voluntas: International Journal of Voluntary and NonProfit Organisations, 10, 197-215.

Harrison, S., \& Smith, C. (2004). Trust and moral motivation: Redundant resources in health and social care? Policy and Politics, 32, 371-386.

Healy, K. (2006). Last best gifts: Altruism and the market for human blood and organs. Chicago ; London: University of Chicago Press.

Jenkins, V., \& Fallowfield, L. (2000). Reasons for accepting or declining to participate in randomised clinical trials for cancer therapy. British Journal of Cancer, 82, 1783-1788.

Kenyon, S., Dixon-Woods, M., Jackson, C. J., Windridge, K., \& Pitchforth, E. (2006). 
Participating in a trial in a critical situation: a qualitative study in pregnancy.

Quality \& Safety in Health Care, 15, 98-101.

Lawrence, B., \& Suddaby, R. (2006). Institutions and institutional work. In S. Clegg, C. Hardy

\& T Lawrence (Eds.), Handbook of organisation studies (2nd edition ed.) London: Sage.

Lowton, K. (2005). Trials and tribulations: Understanding motivations for clinical research participation amongst adults with cystic fibrosis. Social Science \& Medicine 61, 18541865.

Merton, R. K. (1973). The sociology of science: Theoretical and empircal investigations. Chicago: University of Chicago Press.

Meyerson, D., Weick, K. E., \& Kramer, R. M. (1996). Swift trust and temporary groups. In R. Kramer, \& T Tyler (Eds.), Trust in organisations: Frontiers of theory and research. Thousand Oaks Calif: Sage Publications.

Mulder, L. B., Van Dijk, E., De Cremer, D., \& Wilke, H. (2006). Undermining trust and cooperation: The paradox of sanctioning systems in social dilemmas. Journal of Experimental Social Psychology, 42, 147-162.

Offer, A. (1996). The mask of intimacy: Advertising and the quality of life. In A. Offer (Ed.) In pursuit of quality of life Oxford: Oxford University Press.

Olson, M. (1971). The logic of collective action: public goods and the theory of groups. Cambridge, Mass: Harvard University Press.

O'Neill, O. (2004). Accountability, trust and informed consent in medical practice and research. Clinical Medicine, 4, 269-276.

Ostrander, S. (2007). The growth of donor control: revisiting the social relations of philanthropy. Nonprofit and Voluntary Sector Quarterly, 36, 356-372 
Ostrom, E. (1990) Governing the commons: the evolution of institutions for collective action Cambridge: Cambridge University Press

Parker, M. (2005). When is research on patient records without consent ethical? Journal of Health Services Research \& Policy, 10, 183-186.

Potter, J. (1987). In Wetherell M. (Ed.), Discourse and social psychology : Beyond attitudes and behaviour. London: Sage.

Power, M. (1999). The audit society: Rituals of verification. Oxford: Oxford University Press.

Powell, W.W. \& Colyvas, J. (2008) Microfoundations of institutional theory. In: Greenwood R, Oliver C, Suddaby R, Sahlin-Andersson K (eds) Handbook of Organisational Institutionalism. London: Sage

Pruitt, D. G., \& Kimmel, M. J. (1977). 20 years of experimental gaming: Critique, synthesis, and suggestions for the future. Annual Review of Psychology, 28, 363392.

Redfern, M. (2001). The report of the Royal Liverpool children's inquiry. London: Stationery Office.

Sitkin, S. M., \& Roth, N. L. (1993). Explaining the limited effectiveness of legalistic remedies for trust/distrust. Organisation Science, 4, 367-392.

Slevin, M., Mossman, J., Bowling, A., Leonard, R., Steward, W., Harper, P. et al. (1995). Volunteers or victims: Patients' views of randomised cancer clinical trials. British Journal of Cancer, 71, 1270-1274.

Smith, C. (2001). Trust and confidence: Possibilities for social work in 'high modernity'. British Journal of Social Work, 31, 287-305.

Starr, C. (1985) Risk management, assessment, and acceptability. Risk Analysis, 5, 97-102. 
Sztompka, P. (2007). Trust in science: Robert K. Merton's inspirations. Journal of Classical Sociology, 7, 211-220.

Tonkiss, F., Passey, A. (1999) Trust, confidence and voluntary organisations: between values and institutions. Sociology 33: 257-274

Wendler, D., Krohmal B., Emanuel E.J., Grady, C. (2008) Why patients continue to participate in clinical research. Archives of Internal Medicine 168: 1294-1299 